\title{
2 Institutional Design and Human Motivation: The Role of Homo Economicus Assumptions
}

\begin{abstract}
What kinds of behavioral or motivational assumptions are appropriate if "legislators" want to design "good" social institutions or constitutions? David Hume's famous advice has been to follow the maxim "that every man must be supposed a knave: Though at the same time, it appears somewhat strange, that a maxim should be true in politics, which is false in fact." Notice that Hume as well as Adam Smith both argued that humans sometimes and under certain conditions empirically act in accordance with a principle of "sympathy", that is, they are able and willing to take the roles of their interaction partners and identify with their respective interests. Nevertheless, legislators who try to construct efficient social institutions should not assume that such pro-social motives prevail. In contemporary constitutional economics James Buchanan has endorsed Hume's maxim with regard to the design of basic societal institutions: "Homo economicus, the rational, selforiented maximizer of contemporary economic theory, is, we believe, the appropriate model of human behavior for use in evaluating the workings of different institutional orders" (Brennan and Buchanan 1985: 61). The paper evaluates the Hume-Buchanan doctrine in the light of empirical evidence and theoretical insights with respect to social preferences and intrinsic motivations.
\end{abstract}

\subsection{Introduction: Explaining institutions versus. designing institutions}

Institutions are "rules" which affect outcomes of various social interactions. The set of institutions which regulate interactions in modern societies comprises a variety of rules on different levels. There are informal and formal rules like conventions which regulate every-day interactions in traffic situations. Other rules refer to informal norms which call for contributions to public goods ("avoid leaving refusals

Note: Material from this paper has been presented at the Seminar "Rational Choice Sociology: Theory and Empirical Applications" at Venice International University, San Servolo, November 21 - November 24, 2016. Comments by participants of this Seminar and by two referees, in particular by Hartmut Esser, are gratefully acknowledged.

Thomas Voss, Department of Sociology, Leipzig University, Germany

Ә Open Access. (C 2020 Thomas Voss, published by De Gruyter. (c) BY-NC-ND This work is licensed under a Creative Commons Attribution-NonCommercial-NoDerivatives 4.0 International License.

https://doi.org/10.1515/9783110647495-002 
when having a picnic on the green"). More formalized rules are laws and constitutions which have been designed consciously. Online auction platforms like eBay use rules which refer to the auction procedure (e.g., variants of a second-price auction) and to improve incentives to cooperation (e.g., reputation mechanisms) which have been designed and which are continuously monitored and improved. At the multi-national level core actors from different states (e.g., from the European Union) currently design, evaluate, interpret and change rules which are intended to solve severe collective action problems with respect to financial and monetary policy, international migration and others.

Social science and sociology in particular aim to explain the workings, the emergence and effects of institutions. There has been and still is of course a lot of controversy about the theoretical tools and methodology which is appropriate in this context. Durkheim (1895) who defined sociology as the science that has to describe and explain social institutions and other social facts claimed that social facts should be explained by empirical laws on the level of social facts. In this paper, I will adopt, in contrast, the methodological individualistic idea that explaining institutions (that is, social facts on the "collective" or "macro" level) requires micro level assumptions about individual behavior or choices. In some contexts it may be useful to model individual actions by applying ideas which resemble Popper's "logic of the situation" (Popper 1966) or in some other "everyday sense" of rationality and not in the technical sense of axiomatic rational choice theory (Simon 1978). In economics, political science and sociology, however, more technical rational actor assumptions and models were employed with considerable success. The micro model of man until the 1990's has predominantly and more specifically been a version of the homo economicus or rational egoism (RE) conception. There are many variants of this conception but as the two basic ingredients I consider the assumptions of rationality (R) and self-interestedness or "egoism" (E). These ingredients are conceptually and logically independent: $\mathrm{R}$ basically means consistency of preferences (and beliefs) and E means that a particular subset from the extensive set of (logically consistent) preferences is empirically relevant. In other words, social preferences (e.g., altruism, fairness, spitefulness) can be and are in fact presently used in a rational actor model but not in the homo economicus or RE concept. The RE model is the core explanatory component in Coleman's (1990) opus magnum as well as in much of Gary Becker's (1976) seminal economic approach to social behavior. The RE approach is considerably strong in demonstrating the collective effects of social structural and institutional variables. In sociology, there has been an extensive research program based on game-theoretic principles about the structural factors which foster trust and cooperation in "problematic" social dilemma situations. In much of this work, individual behavior is modeled as driven by selfinterested motives and by instrumental rationality which means that behavioral choices are assumed to be consistent with (possibly subgame perfect) Nash equilibria. In social dilemmas there is a contrast between rationality and efficiency 
(in the Pareto sense) among rational egoists. It has been shown by Werner Raub and members of his Utrecht research group that certain social conditions (like repeated interaction with a large "shadow of the future", multiplexity, multilateral reputation and others) may contribute to efficiency gains in social dilemmas (see Raub and Weesie 1990, Raub et al. 2013, Raub 2017; other closely related work in a similar vein is described in Greif 2006; for experimental work that demonstrates fairly good empirical predictions of RE assumptions in the repeated prisoner's dilemma see, for example, Dal Bó 2005). However, as is well known, there has been something akin a scientific revolution within economics and several related fields which casts serious doubts on the empirical and explanatory status of RE assumptions. Early attacks on the RE model focused on the rationality assumption (e.g., transitivity and independence axioms in expected utility theory). In more recent decades laboratory experiments and behavioral game theory apparently demonstrated that (many or some) subjects are motivated by social preferences and not exclusively by self-regarding preferences. For the time being, there seems to be a consensus that empirically valid explanations of institutions must be based on or at least be complemented by behavioral and motivational assumptions which are psychologically more "realistic" than the RE model in that they employ bounded rationality and social (and possibly also intrinsic) motivations (see Ostrom 2005a: Chapter 4; Bowles 2016). However, there is less of a consensus about which particular version of bounded rationality or of social preference functions should be used.

This very rough sketch of the state of the art refers to empirical explanations. The situation may look different if normative questions of institutional design are considered. In his well-known Presidential Address to the American Sociological Association Coleman argued in favor of sociology as a science of design and rational construction of society:

What does this (. . .) mean for sociology and sociologists? It implies a future in the design of organizations, institutions, and social environments - design intended to optimize relevant outcomes. (. . .) It is the task of sociologist to aid in that construction, to bring to it the understanding of social processes, to ensure that this reconstruction of society is not naive, but sophisticated, to ensure, one might say, that it is indeed a rational reconstruction of society.

(Coleman 1993: 14)

Many social scientists still accept Max Weber's postulate of a value-free social science ("Werturteilsfreiheit"). According to Weber's postulate social science cannot legitimately give an ultimate justification for value judgments or normative recommendations. But scientific methods can help to investigate whether two or more normative statements are mutually consistent. Social science can also, and this is a task of eminent practical importance, demonstrate whether and by which means certain normative goals can be realized. With respect to designing institutions, normative social theory may have the legitimate task to provide what has been called 
"hypothetical imperatives" (Harsanyi 1958). In contrast to unconditional categorical imperatives, they contain conditional statements of the form "If you accept certain rationality axioms or if you want to realize certain goals then you should choose alternative X”.

In fact, the basic idea of some prominent neo-contractarian approaches to normative social theory is to use Gedankenexperimente of a "moral decision situation" (Harsanyi) or an "original position" (Rawls) behind a "veil of ignorance" to argue which rules or which principles of justice rational individuals will choose. In addition to such "constitutional" decisions, normative theory might also (and in fact: must) analyze the expected effects of those principles or rules given they will be implemented in a future society or group. Such analyses must be based on assumptions about the social conditions which prevail in the situation as well as the behavioral principles which are at work among the (future) participants of the society. It seems likely that the theory of action which is employed in analyses of constitutional decisions and in analyses of agents' behaviors in a future society will not necessarily be identical. To be more specific, with respect to constitutional decisions one may arguably use rationality principles of the RE type, whereas with regard to post-constitutional decisions behavioral principles of the bounded rationality type can be appropriate.

In this paper, I will discuss the theoretical role of RE assumptions in the context of normative social theory. The main task will be an evaluation of what may be called Hume-Buchanan doctrine of using homo economicus or RE assumptions in institutional design. Prior analyses of the doctrine (Schüssler 1988, Hausman 1998) mainly focus on different critical aspects which will not be covered in the present paper.

\subsection{The RE model and the Hume-Buchanan doctrine}

\subsubsection{Three levels of decisions in institutional design}

In referring to normative social theory, I will confine myself to subjectivist and consequentialist approaches in the following sense. In the tradition of David Hume's moral philosophy or in accordance with Max Weber's idea of a "Verantwortungsethik" normative problems are necessarily explicated by pointing to the subjective interests of the individuals who are the target actors and the beneficiaries of normative or moral imperatives. In the light of this tradition it must be demonstrated that the choice of and the conformity to normative principles is in fact possible and will have consequences which are consistent with the long-term subjective interests of the involved agents. 
It is convenient to distinguish between three levels of decision problems in normative social theory. First, (level 1) there are first order decisions with respect to the criteria institutions should fulfill: Efficiency, maximizing "social welfare", "wealth", just redistribution, profit maximization etc. Secondly, (level 2) there are second order decisions with respect to the choice of specific rules or institutions which are consistent with the criteria (constitutional choice). These rules are designed such that they provide incentives and constraints for the involved (future) agents to realize first order goals. Thirdly, (level 3) one has to deal with third order decisions under the constraints of the level 2 rules. In this case, the "social planner" has the task to analyze individual decisions and collective outcomes of the (fictitious) agents who (in the future) will live under the rules which are implemented in accordance with first and second order decisions (if so). Notice that decisions on levels 1 and level 2 are, so to speak, decisions on a "meta level" which are due to the actors who want to design an institution. Level 3 decisions are on the "object level" which are, however, dependent on the "planner's" selection among models of man.

\subsubsection{Example: Institutional design in migration policy}

To illustrate with a concrete case, consider the example of institutions which regulate refugee and migration policy in the European context. To regulate immigration into the European Community, Betts and Collier (2017) evaluate various institutional solutions (see also Collier 2013). They argue (level 1) in favor of the normative criterion of welfare maximization as a principle that is consistent with utilitarianism. (The set of individuals whose utility levels are to be maximized contains not only prospective migrants but also the people who remain in African or Asian countries ["stayers"] and European citizens. This is a kind of cosmopolitan normative criterion because the welfare (or the utility levels or "happiness") of people from foreign countries is included - not only Europeans' welfare). Evaluating alternative rules (level 2) requires the demonstration of how the rules will affect the dominant actors' incentives (level 3). These agents are (i) political leaders who are faced with collective action problems and incentives to free ride on the supra national level ("let other countries contribute to the costs"), (ii) refugees searching for individually optimal options and (iii) agents ("entrepreneurs") who are interested to engage in smuggling as an (illegal) commercial enterprise.

As another example, I mention reflections on institutional design of immigration from an US American perspective (Posner 2013). As the maximand on level 1 Posner argues in favor of the well-being of Americans. The welfare of American citizens (workers, employers, other citizens) depends on the individual characteristics of the migrants who are selected and who possibly enter the labor market. Social welfare may also be positively affected by migrants whose presence permits family reunification. Furthermore migrants who are willing to integrate or to assimilate 
the cultural and social norms and who thereby will increase (or at least not decrease) society's social capital may be preferred to migrants who are not willing or able to integrate. Migrants of the "good" type contribute to an increase of American welfare, "bad" types do not bring valuable human capital or other good characteristics. In the extreme, bad types, once they have been admitted to stay, may look for a career as beneficiaries of public welfare or even for a criminal career. There are various institutional solutions to screen potential migrants in order to select those persons who are "good" types. The screening methods have to account for asymmetric information problems and reduce the adverse selection and moral hazard problems which can arise if migrants are better informed about their own type than the government agencies that are deciding about admission of migrants. In addition to screening potential migrants, there must also be, as argued by Posner, rules and procedures to control the behavior and rights of migrants. As will be clear to anyone who has thought about the design of institutions in this realm, the rational construction of efficient rules which serve the selected normative goals is extremely complex and cannot be discussed in detail in the present paper. It is, however, clear that analyses on level 2 and level 3 (second and third order decisions) are critically interconnected. To base screening predominantly on educational credentials and other desirable qualifications (language proficiency etc.) that can be easily observed (as is done in the Canadian points system) can have the adverse effect to deny admission to migrants who may be potentially highly motivated unskilled laborers - provided that the country would profit from admissions of some migrants who are unskilled workers. Another problem is that a points system does not help to cope with the control or moral hazard problems after admission has been permitted (see Posner 2013: 303-304). Posner's analysis is based on the assumption that potential migrants are heterogeneous with respect to the distribution of desirable characteristics and that their behavior is rational and motivated by self-interest under the constraints of the rules which regulate admission to the United States. The line of reasoning that is sketched in Posner's contribution is completely consistent with a standard economic (RE) model of man.

\subsubsection{Designing “just" or morally "good" institutions}

Given that the outcomes of institutions should meet certain (normative) criteria, social theory can define its task as the specification and evaluation of institutions. There are of course well-known attempts to address this task with respect to the basic constitutional institutions such that these institutions meet criteria of moral reasoning. In moral theory, Harsanyi and Rawls, among others, asked which kinds of general principles and rules meet moral standards of fairness or impartiality. This problem refers to first order and second order decisions. Harsanyi and Rawls both adopted a rational actor approach, albeit in slightly different ways. The actors 
are envisioned in a Gedankenexperiment as agents behind a "veil of ignorance" such that they choose rules as if they did not knew which social position they will occupy within the (future) society that will realize concrete institutions under the constraints of the chosen universal principles. Harsanyi $(1976,1977,1978)$ argued in favor of Bayesian rationality (expected utility maximization) and demonstrates that rational agents in a "moral decision situation" will necessarily choose institutions which maximize the aggregate welfare as measured by the sum (or arithmetic mean) of the cardinal utilities of the individuals. This approach of course requires that there are theoretically sound methods to interpersonally compare individual utility levels. The normative principle which emerges as an outcome of Harsanyi's moral decision situation is consistent with utilitarian ethics, in particular "rule utilitarianism". Harsanyi's approach is silent about the concrete institutions which help maximize utilitarian welfare functions. Rawls (1971), in contrast, argued that agents will be extremely risk averse in the "original position" of this constitutional choice situation. They will therefore, according to Rawls, use the maximin criterion of decision theory. This line of reasoning and some additional arguments build a justification for Rawls' so-called "difference principle" which implies that just institutions should guarantee that - if social inequalities cannot be prevented or would be inefficient in the Pareto sense - society allocates primary goods such that the welfare level of incumbents of the most disadvantaged positions is maximized (compared to the elements of the set of alternative institutions). Rawls' approach consequently is less abstract than Harsanyi's in that it points to more concrete institutions (like equal opportunity in education) of modern societies which work in the direction of realizing the goals which are expressed in the principles of justice. This, however, comes at the cost that it is doubtful whether the relevant agents on level 3 of third order decisions in fact will want to or will be able to enforce the required policy recommendations (for instance with respect to the organization of educational systems) (see Coleman 1974 for an elaboration of this critique).

In a similar vein, constitutional economics as developed in the Public Choice School asks which basic constitutional rules rational agents behind a "veil of uncertainty" would choose. The rules which are chosen refer to situations of collective action and rules of collective decision-making in some future situation. As a case in point think about individuals who decide about whether to allocate economic resources by markets or by bureaucratic organizations. Persons who presently are successful entrepreneurs may of course have different personal interests than members of a public organization that is developing or enforcing laws to regulate market behavior. The latter expect better career prospects if the amount of bureaucratic regulation is strengthened. The rationale of a veil of uncertainty is to secure a certain degree of impartiality such that the decision is devoid of immediate selfinterest. In Buchanan's approach "persons are modeled as though they were faced with choices among rules of social order that are generally applicable and guaranteed to be quasi-permanent. By comparison, the Rawlsian 'veil of ignorance' is an 
idealized normative construction, the appropriate starting point for persons when they consider making choices among basic principles of justice” (Brennan and Buchanan 1985: 35). Choosing among rules behind a veil of uncertainty means that "the interest of any person or group is much less easily identified" than in the choice within the set of rules (in the post-constitutional decisions). This is so because "rules are, almost by definition, applicable to a number of instances or cases" and because rules "embody an extended time dimension. The very notion of a rule implies existence through a sequence of time periods" (Brennan and Buchanan 1985: 35). As an example, Buchanan considers balanced-budget rules which restrict democratic governments' discretion with respect to public debt. Buchanan argues that the amount of conflict of interest among agents choosing among basic constitutional rules (level 1 and level 2) will be much lower than in decisions within the set of rules (level 3). Agreement will therefore be reached more easily and often unanimously.

\subsubsection{Three levels of decisions in designing "just" or morally "good" institutions}

To reiterate, there are three analytically distinct levels of decision problems which are involved in institutional design. On all three levels the choices of possibly multiple heterogeneous agents must be modeled (members of a constitutional assembly, directors of an enterprise, members of a political party etc.). In contractarian approaches to morality and in constitutional economics, the multiplicity of personal interests and their potential conflicts are reduced by imposing the fiction of a veil of ignorance or uncertainty. It may be argued that the veil will potentially (empirically or in light of abstract rationality) generate a consensus or a unanimous decision of different agents. The decisions on this level may then be analyzed by treating the decision-making body as a single representative individual. Given the restrictions of a veil, the decisions are considered in these approaches as consistent with rationality axioms of Bayesian decision theory and game theory (Harsanyi) or neoclassical economic theory (Buchanan) or a particular non-Bayesian conception of individual rationality (maximin) with extreme uncertainty (Rawls). In Harsanyi's work (1977) which contains a precise explication of the concept of a moral decision, each involved agent (on level 1) is uncertain about her future social status or position in society and assigns an equal probability to each outcome (in terms of status positions). She then chooses the set of rules that maximizes her expected utility (in terms of von Neumann-Morgenstern utility functions). There is no need to assume altruism or other social preferences at this point because even perfectly selfish individuals under the constraints of the veil will choose rules which maximize the social welfare as defined by utilitarian criteria (sum of personal utilities of all involved individual positions). 
It is, however, debatable whether and under which conditions rational selfinterested individuals will want to enter a decision situation behind a veil of ignorance or uncertainty and will want to commit themselves to accept the set of rules which have been selected before in the constitutional stage. As many critics have emphasized it may even be debatable whether or not real humans will in fact attain a consensual decision on this level (see, for example, Coleman 1974, 1990). Thus, on level 1 it is assumed that behavior (behind a veil) is governed by principles of rationality in the RE sense (or homo economicus sense). Referring to second and particularly third order decisions Buchanan's constitutional political economy is most explicit. Arguments on level 3 require that the social scientist has to compare the empirical effects of various institutional arrangements with respect to the desired outcomes. This means that appropriate assumptions with respect to actors who choose within the set of rules must be employed. It is important to note that decision-making on level 1 has to take into account second and third order decisions. Table 2.1 gives an overview on the three levels and some illustrations.

Table 2.1: Three levels of choices in institutional design.

\begin{tabular}{|c|c|c|c|}
\hline & Decision-making agent(s) & Constraints & Set of alternatives \\
\hline $\begin{array}{l}\text { First order } \\
\text { (level 1) } \\
\text { decisions }\end{array}$ & $\begin{array}{l}\text { Subject(s) who design institutions: } \\
-\quad \text { general citizenship } \\
-\quad \text { constitutional assembly } \\
\text { - } \quad \text { political decision-making body }\end{array}$ & $\begin{array}{l}\text { "Moral situations": veil } \\
\text { of ignorance (Harsanyi, } \\
\text { Rawls) } \\
\text { "Constitutional } \\
\text { choices": veil of } \\
\text { uncertainty (Buchanan); } \\
\text { Collective decision- } \\
\text { making rules; } \\
\text { Other physical or social } \\
\text { constraints and } \\
\text { resources }\end{array}$ & $\begin{array}{l}\text { Universal principles } \\
\text { of justice; } \\
\text { Maximands of } \\
\text { individual and or } \\
\text { social welfare }\end{array}$ \\
\hline $\begin{array}{l}\text { Second } \\
\text { order } \\
\text { (level 2) } \\
\text { decisions }\end{array}$ & $\begin{array}{l}\text { Subjects who design or implement } \\
\text { institutions }\end{array}$ & $\begin{array}{l}\text { Universal principles and } \\
\text { criteria which } \\
\text { institutions should fulfill }\end{array}$ & $\begin{array}{l}\text { Concrete } \\
\text { realizations of first } \\
\text { order choices: } \\
\text { institutions }\end{array}$ \\
\hline $\begin{array}{l}\text { Third order } \\
\text { (level 3) } \\
\text { decisions }\end{array}$ & $\begin{array}{l}\text { Subjects who live under the } \\
\text { constraints of institutions }\end{array}$ & $\begin{array}{l}\text { Institutions as realized } \\
\text { outcomes of first } \\
\text { and second order } \\
\text { choices }\end{array}$ & $\begin{array}{l}\text { Opportunity set } \\
\text { under the } \\
\text { constraints of } \\
\text { institutions }\end{array}$ \\
\hline
\end{tabular}

To illustrate, designing rules with respect to immigration policy not only requires decisions about the normative criteria and goals which should be reached but must also include predictions about the likely effects of these rules given the cognitive 
and motivational capacities of the various involved agents who will act under the institutions. Thus all three decision levels are interconnected.

\subsubsection{The Hume-Buchanan doctrine}

Referring to institutional design Buchanan and Brennan approvingly quote David Hume's famous advice to follow the maxim "that every man must be supposed a knave: Though at the same time, it appears somewhat strange, that a maxim should be true in politics, which is false in fact" (Hume 1741: 42-43). Notice that Hume as well as Adam Smith both argued that humans sometimes and under certain conditions empirically act in accordance with a principle of "sympathy", that is, they are able and willing to take the roles of their interaction partners and identify with their respective interests. Nevertheless, legislators who try to construct efficient social institutions should not assume that such pro-social motives prevail. In contemporary constitutional economics Buchanan and Brennan endorsed Hume's maxim with regard to the design of basic societal institutions as follows: "Homo economicus, the rational, self-oriented maximizer of contemporary economic theory, is, we believe, the appropriate model of human behavior for use in evaluating the workings of different institutional orders" (Brennan and Buchanan 1985: 61). Interestingly, this doctrine is justified not primarily by the empirical "realism" or adequacy of the model of man but by using rationality behind the veil: Since we are uncertain with respect to properties (in particular preferences and information) of the relevant actors who in future instances will act under the restrictions of the constitutional rules we should use the decision rule of a "quasi risk aversion" when deciding among various models of man: "Our claim is that because of the nature of what is to be evaluated, the gains attached to an 'improvement' secured by departures of behavior from the modeled are less than the losses imposed by corresponding departures of behavior in the opposing direction, that is, toward behavior worse than that represented in the model itself" (Brennan and Buchanan 1985: 63). The rationale for this normative maxim is not that human behavior is empirically governed by rational egoism under all circumstances but that even in populations with a majority of actors who are endowed with pro-social motivations these motives may be driven out: "the narrow pursuit of self-interest by a subset will induce all persons to behave similarly, simply in order to protect themselves against members of the subset” (Brennan and Buchanan 1985: 68). In other words, if institutional rules are designed under the premise of prosocial behavior of the target actors (who are supposed to follow the rules) there is a risk to trigger a crowding out process with respect to these motivations ("Gresham's law of politics”). 


\subsection{Anomalies and the Hume-Buchanan doctrine}

\subsubsection{The RE model of man and its anomalies}

It may be useful to classify models of man along two dimensions: Rationality and motivation (preferences). The homo economicus or RE model is first characterized by (1) selfish motivation. This means that actors are outcome-oriented and self-regarding. Outcomes of behavior may be non-material such as units of social approval and status received in social exchanges. (2) The second dimension is (the degree of) rationality. Neoclassical price theory assumes complete and consistent preferences and perfect information-processing abilities. In Bayesian game theory many other capacities are built into the model: behavior in accordance with subjective expected utility maximization axioms (of Savage), common knowledge of rationality, backward induction.

To be more specific, rationality means that agents choose among alternative courses of action in accordance with certain basic assumptions and more specific criteria (rationality axioms). The most general background assumptions are consequentialism and invariance. Consequentialism (in the descriptive sense) in this context means that actions are selected in accordance with (expected) future consequences. This rules out the consideration of "sunk costs" or other features related to investments in the past as far as they are irrelevant for future outcomes. Invariance means that alternatives are evaluated and selected irrespective of how these alternatives are presented ("framing").

Standard rational choice theory, and homo economicus assumptions in particular, have of course been targets of severe criticism for being empirically inadequate. Behavioral economics and cognitive psychology have produced a great deal of empirical evidence, mostly laboratory experiments, which seem to demonstrate limitations of RE assumptions, at least on the micro-level of individual choice behavior. It has been questioned that this evidence is consequential for the analysis of real-world problems outside the laboratory (Levitt and List 2007, 2008). However, some evidence from field experiments and case studies suggests that the set of behavioral assumptions which are useful in empirical explanations of institutions must be more comprehensive than the standard homo economicus concept (see Ostrom 2005a, b).

According to prospect theory, preferences (as represented by a "value function") are situation dependent. Alternative amounts of wealth are evaluated as changes of wealth. If the change is "framed" as a "gain" compared to a reference point (status quo), the curvature of the value function is concave ("risk aversive"); "losses" are evaluated by means of a convex function ("risk-seeking"). In addition to framing, prospect theory also deals with other anomalies, e.g. problems related to a basic axiom of expected utility theory, viz. the independence assumption. The famous Allais paradox demonstrates that preferences over risky prospects are not linear in probabilities (Machina 1987); prospect theory postulates preferences and probability functions which cope with this problem (see Kahneman and Tversky 1986). 
Behavioral economics pointed to several further problems of the RE model. Consequentialism has been shown to be violated by evidence on sunk cost effects (see Thaler 1980, 2015). There are also some other behavioral anomalies, some of which can be explained by prospect theory (e.g., endowment effect).

With regard to motivational assumptions, behavioral game theory seems to demonstrate that the assumption of self-regarding preferences is empirically questionable, at least a considerable proportion of participants in game experiments are acting as if they had social preferences. Numerous experiments on ultimatums, prisoner's dilemmas and linear public goods reveal that many subjects do not choose actions or strategies such that they maximize monetary payoffs (as homo economicus would).

In addition to social preferences which, for example, depend on outcomes of members of ego's reference group (like altruism, inequity aversion or envy) and not only on ego's own material payoffs, there is an extensive body of work on "intrinsic" motivation. Humans may be motivated to perform certain actions because these actions are valuable per se. Under certain conditions intrinsic preferences (for example, to cooperate) will be crowded out if external interventions provide material rewards or punishments. There is anecdotal and experimental evidence from psychology and also, but less so, from experimental economics which demonstrates such crowding out effects. One can argue that in cases of intrinsic preferences a central assumption of neoclassical economics is violated, namely additive separability (Bowles 2016). In the context of intrinsic preferences this means that externally provided incentives and intrinsic motives to perform an action do not work additively but there may be interferences such that external incentives on the one hand increase the tendency to choose the relevant action and on the other hand reduce the strength of intrinsic motives. The total effect may be in the extreme such that the propensity to perform the desired action is reduced due to the incentives - contrary to the goals which the "social planner" wants to accomplish. As a case in point consider the effects of intensive external monitoring or variable rewards (piece-rate payments) on workers who have been, prior to the intervention, intrinsically motivated to perform their tasks. In such cases, it may well be that interventions decrease the quality and quantity of workers' outputs because they undermine intrinsic motivations.

An overview on selected anomalies is given in Table 2.2.

Table 2.2: Empirical anomalies of the RE model of man.

\begin{tabular}{lll}
\hline RE Assumptions & Anomalous effects & References (sample) \\
\hline I. Rationality (R) & & \\
\hline $\begin{array}{l}\text { Consequentialism } \\
\text { (Outcome-orientation) }\end{array}$ & Sunk cost effects & $\begin{array}{l}\text { Thaler 1980; Thaler 2015: } \\
\text { Chapter 8 }\end{array}$ \\
\hline Invariance & Situation dependent preferences: Framing & $\begin{array}{l}\text { Kahneman \& Tversky 1986; } \\
\text { Kahneman 2011 }\end{array}$ \\
\hline
\end{tabular}


Table 2.2 (continued)

\begin{tabular}{lll}
\hline RE Assumptions & Anomalous effects & References (sample) \\
\hline Independence Axiom & Allais paradox & Machina 1987 \\
\hline II. Motivation (E) & & \\
\hline Selfish Preferences & $\begin{array}{l}\text { Behavioral Game Theory: Social preferences } \\
\text { (Ultimatum, Public Goods with Punishments } \\
\text { experiments) }\end{array}$ & Camerer 2003 \\
\hline $\begin{array}{l}\text { Separability of } \\
\text { extrinsic and intrinsic } \\
\text { rewards }\end{array}$ & $\begin{array}{l}\text { Intrinsic Motivation: Crowding out- effects } \\
\text { of material incentives }\end{array}$ & $\begin{array}{l}\text { Frey 1994; Bowles and } \\
\text { Polania-Rayes 2012; Bowles }\end{array}$ \\
\hline
\end{tabular}

\subsubsection{The RE model is not the "worst case"}

\subsubsection{Anti-social motives}

With respect to motivational assumptions is the RE model in fact, as the HumeBuchanan doctrine supposed, the "worst case" assumption? The idea is that different social institutions which regulate peculiar "problematic" social situations can be analytically matched with various distributions of individual preferences (self-regarding vs. social preferences of various kinds). Then various combinations of preferences with institutions generate different outcomes which can be evaluated normatively. Now, not every logically possible combination of individual preferences is empirically relevant. Some authors indeed have argued that the set of individual preferences can analytically be reduced to those utility arguments which are shared by every human being and related to a stable subset of basic commodities (see Becker 1976). However, some experiments reveal that indeed altruism, fairness but also anti-social preferences are effective. Yet, for the time being, we do know next to nothing about the empirical distribution of preferences in various situations. In some social contexts laboratory experiments have evoked an emotional reaction of spitefulness and costly punishment against target actors who contributed to public goods (Herrmann et al. 2008). If those motives prevail, the opportunity to punish free riders (and possibly also cooperators) in a public goods situation yields inefficient outcomes. It thus seems that self-interestedness is not always the worst case.

\subsubsection{Choice anomalies}

With respect to behavioral anomalies which reflect limits of rationality it is tempting to ask whether the complete rationality assumption is indeed a worst case. Consider 
an anomaly like the sunk cost effect. An agent who knows that she is not immune to such effects when she deals with everyday operational decisions but who wants to maximize her personal welfare will want to commit herself to rules which prevent her from trapping into sunk cost fallacies. These institutions would serve to improve outcomes of RE's in terms of their material interests. This means the homo economicus model is not the most pessimistic ("worst case") model because anomalies can yield individually and/or collectively suboptimal outcomes. The general point thus is as follows: Homo economicus is not the kind of person whose behavior is prone to behavioral anomalies. However, ordinary people who want to realize self-regarding preferences will want to live under the constraints of rules which cope with their limits of rationality. In fact, the very idea of "liberal paternalism" and "nudging" (Thaler and Sunstein 2008) is to improve everyday decisions (the criterion of improvement is the realization of RE preferences). But this implies first and second order decisions which are by and large consistent with the RE model. Thus, the nudging approach is a conception of institutional design which rests on the idea that rules should be superimposed on boundedly rational agents who want to attain better outcomes in terms of self-interested preferences.

\subsubsection{Crowding out effects: Gresham's law of politics versus other crowding out effects}

A central argument that is used to support the Hume-Buchanan doctrine is based on what Brennan and Buchanan (1985: 68) call Gresham's law of politics. Suppose a set of rules produces "good" or efficient outcomes provided a large fraction of the population of actors who act under the constraints of these rules are endowed with pro-social preferences. Then it is likely that a crowding out process takes place such that pro-social motives gradually disappear from the setting provided self regarding actors are more successful in this situation. This being the case, it seems that rationality requires as a "quasi risk averse" choice of the model of man to use the RE model in analyses of third order decisions. Though there is some supporting evidence for this kind of social dynamics (see, however, Schüssler 1990 for some caveats) other types of crowding out processes have been studied extensively.

In addition to crowding out processes, it may also be the case that crowding inprocesses take place. For instance, if a critical mass of pro-social agents is clustered within a population of RE agents and if the pro-social agents (much) more frequently interact with one another than with the remaining population, they may in long term drive out the self-regarding agents because they are more successful. This process has been described in various contributions to evolutionary dynamics, for example group selection approaches (see Gintis 2017: Chapter 9 for a discussion of these mechanisms based on a debatable adoption of group selection ideas). 
Psychological mechanisms which lead to driving out processes are another important case in point. Given that an agent is intrinsically motivated to perform certain desirable actions, it may well happen that external interventions via the provision of extrinsic material rewards or threats of punishments will drive out the motivation to a considerable degree. External interventions perceived as controlling can reduce intrinsic motivation. There are also crowding in effects: In some cases intrinsic motivations may be fostered by interventions which are perceived as supportive. Effects of this kind have been studied by psychologists experimentally with children who reduced their effort to perform certain tasks after ostensive observation and or material incentives had been introduced. More recently, some evidence from experimental games seems to support these effects (for a review and explication of some experimental results see Bowles 2016: 39-77). It seems safe to say that institutional design based on the provision of material incentives has to account for such crowding out processes (for an extensive overview of the literature see Underhill 2016). Depending on the particular parameters of the situation the provision of extrinsic incentives can result in an absolute reduction of intrinsic motives within the individual. In cases of severe reductions of intrinsic motivation, the total effect of both, intrinsic and extrinsic incentives, may be such that the desirable behavior is repressed. In other words, the imposition of rules via external incentives can be counterproductive provided that a significant proportion of the population is endowed with intrinsic preferences which favor the desired behavioral outcomes.

\subsubsection{Social preferences and institutional design}

There is some evidence that social preferences exist even in market contexts. Online auction platforms are certainly products of conscious institutional design. The online transaction company eBay uses not only auction mechanisms which have been adopted from mechanism design theory which is based on the RE model of man. But in addition, eBay created and implemented institutions to cope with trust and cooperation problems that arise in online transactions between partners who in general cannot rely on the shadow of the future or a shadow of the past because exchange is not repeated. The use of multilateral reputation is of course not new but has been standard in commercial relations in economic history since a long time (Greif 2006). eBay uses a feedback system such that buyers can evaluate their partner after the transaction is completed and that this evaluation diffuses throughout the system. The whole community of market participants can in principle use the reputation scores attached to a prospective partner before deciding to interact with that partner. As far as we know, eBay modified its institution several times in order to make it immune against fraud. Until 2008 it was not only possible for buyers to evaluate the seller's trustworthiness but sellers could also evaluate buyers. This led to some problems due to a kind of negative reciprocity: Sellers 
responded to negative feedback by retaliating and giving a negative evaluation even in cases that the buyer's behavior had been exemplary correct. This problem was mitigated via institutional reform but the feedback system still relies on motives which cannot be assumed as prevailing among RE agents. Why should an RE buyer evaluate her partner at all? Giving a feedback is profitable only for the community of future (potential) transaction partners of the focal seller. It is not valuable to the evaluator (assuming that he will not repeat a transaction with the same partner) who has to bear a low cost if thinking about and in fact giving feedback. In other words, to evaluate is comparable to contributing to a public good. Since there are in general no material incentives for giving a feedback, the workings of the reputation system depend to a certain degree on the pervasiveness of social preferences among the users of the platform. There is evidence that in fact a majority of eBay users gives feedback (Bolton et al. 2013, Diekmann et al. 2014). The general point is this: Some institutions depend on voluntary contributions to public goods and work fairly well even though there is no material compensation for cooperation. There apparently is a critical mass, if not a large majority, of participants who display behavior that is based on social preferences. Another institution that heavily depends on voluntary cooperation is of course democratic voting. Still another is participation as a respondent in survey research interviews or questionnaires.

\subsection{Why RE assumptions are useful in institutional design}

\subsubsection{First order and second order decisions and rationality}

Choice anomalies due to limited rationality and non-standard motivations are relevant and must be considered in designing institutions. This does, however, not imply that the RE model is obsolete. Consider first choice anomalies like sunk cost effects. As has been argued, these anomalies create a demand for rules that serve to help overcome the resulting individual or collective inefficiencies. The "nudging" program's aim is indeed to supply those rules: "A nudge is some small feature in the environment that attracts our attention and influences behavior. Nudges are effective for humans, but not for Econs [RE agents, T.V.], since Econs are already doing the right thing. Nudges are supposedly irrelevant factors that influence our choices in ways that make us better off”(Thaler 2015: 326). Evaluating the suboptimality of anomalous behavior is thus, according to the nudging approach, based on the RE model. Nudging therefore rests on the assumption that third order decisions are boundedly rational. The goals of institutional design (first and second order decisions) are, on the other hand, determined by applications of the homo economicus model. 


\subsubsection{Unclear effects of intrinsic motivation}

According to the RE model agents systematically react on external incentives. Rules which change relative prices of alternatives are powerful tools for behavioral change ("power of incentives"). This is, in essence, the basic idea of the law of demand of standard neoclassical microeconomics. Assuming institutional design is based on this idea and that there are (also or entirely) agents who are (without being provided with external incentives) motivated to perform the desired action per se, there will be a chance that crowding out takes place. The effects of interventions via rules or regulation must, however, be analyzed with care: The total effect can be decomposed into the direct effects of extrinsic and intrinsic incentives plus an indirect effect (possibly crowding out). It is obvious that the direction (sign) and strength of the total effect depends on the values of each of the three parameters. It may be that an indirect effect of extrinsic incentives on intrinsic motives is strong enough to offset the direct effect which results in a negative total effect. This is the most severe crowding out effect. Other cases are logically possible, for instance, crowding in effects such that incentives reinforce the effects of intrinsic motivation. This may occur if incentives are perceived as supportive. The central questions are: Is there any reliable ex-ante information about whether social and intrinsic preferences will exist and persist at all? If so, what can be known about the exact distribution and strength of these motivations for different social settings? Since laboratory and field experiments have, for the time being, generated results which are somehow inconclusive or context-dependent, these questions have no clear answer.

It has been argued that evidence from laboratory studies is far more supportive for the impact of non-standard motivational factors than field experiments (Levitt and List 2008). In the latter context, the power of material incentives seems more effective. A particularly well researched area has been employment relationships and the impact of pay-for-performance or piece-rate payments. In certain contexts where one may conjecture that a significant proportion of laborers is intrinsically motivated to supply high levels of effort (e.g., teaching or research and development) pay for performance may indeed be counterproductive in that it elicits poor "quality" and yields an increase in cheating behavior (Jacob and Levitt 2003). Besides crowding out, these counterproductive effects have been mostly attributed to difficulties in measuring work quality and in providing inappropriate indicators for performance.

On the other hand, there exists supportive empirical evidence on the power of incentives in this particular context. From a famous natural experiment clear evidence emerged on increases in effort (without loss of work quality) which could be attributed to the introduction of piece-rate payment (Lazear 2000). The study population was employees of an auto glass repair corporation who prior to the intervention received hourly wages for delivering an acceptable level of output. Quality of work seemed not to be relevant because insufficient quality would be detected 
immediately. There was no indication of intrinsic motivation on the side of the workers. Increases in average output per worker resulted from two mechanisms: First, individual effort was enhanced. Secondly, there was a sorting of high-effort workers who preferred to stay with the firm or were hired, whereas other workers looked for jobs at different firms.

\subsubsection{Institutional domains: Market competition and corporate actors}

There are thus situations where the assumption that the agents are to a significant degree endowed with social or intrinsic preferences which are related to the desired outcome (productivity, cooperation, etc.) does not seem likely. To argue more systematically, there are certain institutional domains where the relevant actors' motivation functions obviously do not depend on other-regarding or intrinsic preferences. The mechanisms which are at work in these domains are market competition, learning and the formalization of standard operating procedures which constrain agents' behavior. Consider anonymous markets without trust problems. In certain areas of the financial industry, and in financial markets in general, the RE assumption is likely a plausible and empirically fruitful first approximation to manage problems of institutional design. In recent years many commentators from the financial press complained about certain adverse phenomena and social dilemmas: With respect to computerized high speed trading of stocks and derivatives there is obviously a severe arms race analogous to a Prisoner's dilemma. Trading firms compete with each other about the fastest connection to Wall Street or other stock exchanges and invest substantial resources to become some fraction of a second faster than their competitors. This gives rise to extra profits by "sniping", that is, by exploiting informational advantages. For example, if a trader gets the information that Apple stock prices increase in New York, her automated ordering system can place orders in Chicago within milliseconds where the prices will similarly rise with a small time lag. However, this competitive advantage vanishes if other traders use similarly quick connections and automated trading software. Another problem is criminal behavior called "spoofing" which is not easily detected and punished by legal sanctions (Ford 2016). This means to place (so to speak fake) buying or selling orders which change the price of some stock. Some milliseconds before the order is scheduled to become executed the spoofer cancels the order and can collect an extra profit by simultaneously selling or buying mirror stock that he previously has acquired.

Possible interventions are the imposition of a small fee on all cancelled trades above a certain limit or to require a minimum rest time before orders to remain open. These new rules would probably not completely reduce opportunism or wasteful investments into rat races but mitigate the problems to some degree. Regulations of this kind would change the behavior of traders by the power of relative prices or 
opportunity costs. Other instruments which rest on attempts to change traders' preferences, moralizing, or appeals to some code of honorable trading behavior (or the attempt to change the "culture" of the financial or investment banking sector) will as far as we know not work. There is also probably no risk that some "intrinsic motivation" to act honorable will be crowded out by such interventions.

In social theory, James Coleman $(1982,1990)$ has advanced the concept of "corporate actors" and of an "asymmetric society". Modern societies are increasingly dominated by corporate actors like capitalist organizations. There is an asymmetry in power in relations between natural persons and these corporate actors. Interestingly, Coleman explains corporate action by means of the RE model. However, natural persons' inferior power position is in part due to the fact that they are, according to Coleman, subject to choice anomalies, for example weakness of will and time inconsistency. These anomalies are systematically exploited by corporate actors. To illustrate, in certain business relationships corporate actors supply their customers with contracts which contain default options with respect to quitting the relation, payment or protection of data privacy. As is well known from behavioral research, opting out from a default option is chosen much less frequently than simply to accept the default option (a prominent example is rules of organ donation). This may be explained by choice behavior on the side of natural persons that is largely consistent with the RE model (costs of switching to an alternative) or, which is somewhat more intuitive, by weakness of will or other types of choice anomalies. One might say that many corporate actors have tacitly or intentionally employed some of the rules and recommendations of the nudging approach in order to further profit interests. In other words, corporate actors have rationally designed institutional rules and contracts with the goal to maximize corporate profits (first and second order decisions) under the assumption that natural persons' behavior is subject to certain choice anomalies (third order decisions).

In the spirit of Coleman's approach, it may be a legitimate goal of normative social theory to provide the public with recommendations on how to improve the power of natural persons in their relations with corporate actors. It would be beside the point to create rules on the assumption that the behavior of capitalist corporate actors (or Weberian bureaucratic organizations more generally) is governed to a significant degree by social or intrinsic preferences. There is indeed some empirical evidence that natural persons are inclined to act more opportunistically vis-à-vis corporations. Individuals tend to frame their interactions (e.g., contracts) with corporate actors much less in terms of morally neutral exchanges than interactions with other natural persons (Rai and Diermeier 2015).

\subsubsection{An excursus on low cost effects}

One might argue that the power of relative price changes is confined to the domain of markets and capitalist corporate actors. However, there is an intensive discussion 
in rational choice sociology about the so-called low cost hypothesis in everyday environmental behavior. The debate set off from papers by Diekmann and Preisendörfer (2003). Though the focus has predominantly been on environmental behavior (by natural persons), the low cost phenomenon occurs in other contexts too where moral or other normative attitudes interact with material interests.

Starting point have been empirical findings based on survey research data:

1. Normative standards have a positive effect on pro-environmental behavior

2. Costs of pro-environmental behavior negatively affect behavior

3. Interaction effects: The positive effect of norms declines with increasing costs

Crediting Douglass North and other economists, Diekmann and Preisendörfer proposed the so-called low cost hypothesis to explain the observation of a discrepancy between normative attitudes (as measured by interview responses) and factual behavior: Words are cheap, but deeds can be very costly. Besides papers by Diekmann and Preisendörfer, many other contributors proposed theoretical explanations of the low cost hypothesis (for an overview and discussion see Best and Kroneberg 2012; Tutic et al. 2017). Some of them have used rather complicated variants of rational choice or of framing reasoning (Best and Kroneberg 2012). Tutic et al. (2017) present a parsimonious explanation based on a simple application of classical demand theory which is a slightly modified variant of a RE-model. The idea is to use a Cobb-Douglas utility function (a tool which was, by the way, also used in Coleman's [1990] analyses of the linear system of action).The utility arguments comprise two normal goods, namely a composite good measuring the amount (quantity) of pro-environmental or other activities related to some normative standard, $x_{a} \geq 0$, and another good $x_{\neg a} \geq 0$ which is unrelated to the attitude or normative standard:

$$
u\left(x_{a}, x_{\neg a}\right)=x_{a}^{\alpha} \cdot x_{\neg a}^{1-\alpha}
$$

Exponents $\alpha \in(0,1)$ measure the strength of the attitude. It is easily shown that by maximizing this function under the conventional linear budget equation that is used in neoclassical demand theory one can derive the three empirical regularities. One of them is of course the classical law of demand: The larger the relative prices of behavior that is related to the attitude or normative standard the lower the demand for this behavior. Notice that the low cost hypothesis is not identical to the law of demand but also contains a hypothesis postulating an interaction effect. This interaction is also easily derived from the Cobb-Douglas-function approach. Empirical evidence indicates that the low cost hypothesis is not universally valid (see Best and Kroneberg 2012 for references). The Cobb-Douglas approach of course depends on preferences which are related to some normative standard. Given that parameter $\alpha$ is very low or even equals zero, there will not be any effects of normative standards at all. It is an empirical question whether or not there are conditions such that extremely high costs do not suppress "moral” behavior. In cases like 
these alternative explanatory approaches based on "framing" may be appropriate (see Esser and Kroneberg 2015).

Some further insights are implied by this kind of comparative statics. Interventions which reduce the relative price of desired moral behavior will increase the amount of that behavior and vice versa. (This may be considered as a kind of crowding in effect.) One may of course use the whole technical apparatus of the Slutsky equation to describe other effects in more detail. It is furthermore possible to make the model more "realistic", for example by introducing a full income constraint in terms of costs of time (which makes sense because many pro-environmental activities will yield direct costs in terms of time and opportunity costs in terms of reduced wages or leisure time).

It is in general not necessary to introduce some more or less complicated framing model to explain the stylized low cost effects. In other words, institutional design may be based on a slightly modified RE model that accounts for specific normative or pro-social attitudes without eliciting crowding out effects.

\subsubsection{The power of incentives}

With respect to institutional design, the homo economicus model suggests interventions which change the relative prices of alternatives such that in the aggregate a socially desirable outcome will be realized. Economics appeals to the so-called generalized law of demand in this case: If the relative price of a good increases, the demand for this good will decrease. In other words: Individual demand functions are negatively inclined. The implementation of these interventions is, in principle, simple because restrictions can be much better manipulated than preferences. From the analysis of the low cost hypothesis, which has been sketched, it follows that relative price effects can work even in cases where the affected individuals hold certain pro-social or moral attitudes. The analysis was comprised to a single (representative) individual agent. It is, however, easily demonstrated that in the aggregate the same qualitative effects can be predicted: Aggregate demand functions which are simply derived by a summation of individual demand curves will show the same qualitative property of a negative slope. The negative slope of the aggregate demand function does not depend on specific preferences.

An important result in this context has been proved in a seminal paper by Becker (1962, reprinted in 1976). If there are $n$ agents who are restricted to choose a bundle of goods which is on their budget line, the negative slope of the aggregate demand function even follows for "irrational" behavior of the participants. Irrationality means that choices are selected at random (impulsively) or inertial (routinely). In other words, on the macro level of aggregate behavior the power of incentives is still preserved if agents are irrational. Even when dealing with "irrational" agents, the RE model can be an appropriate instrument (for the analysis of third order decisions) in designing institutions. 
Developing this point further, notice that in contrast to RE models of third order decisions the macro consequences of limited rationality models or of social preferences utility functions are by no means clear. Many critics have noted that virtually any empirical observation on the individual level can be "explained" ex post by an ad hoc behavioral model. On the other hand, for many if not most "psychological" theories of individual behavior the aggregate consequences are far from clear. It is in many instances not possible to generate inferences on the level of collective effects via applying behavioral theories. Take for example the KahnemanTversky prospect theory. Though this theory is explicated with relatively great precision, it is not yet possible to systematically generate insights for strategic interaction situations. The reason is that prospect theory is not easily linked to game theoretic equilibrium concepts and therefore does not contain a heuristic for micro-macro transitions. What can be done is to translate specific theoretical components of prospect theory, for example assumptions about framing on the curvature of the value function (gain frames induce concave utility functions), into a game-theoretic context (see Raub and Snijders 1997 for such an approach). Alternatives to RE models have not yet evolved into a coherent, unified and parsimonious theoretical instrument to accomplish micro-macro-aggregations. Even proponents of behavioral theory have to concede that "for comparative static predictions of aggregate behavior, self-interest models may make empirically correct predictions because models with more complex motivational assumptions predict the same outcome" (Falk and Fischbacher 2005: 183).

\subsection{Conclusion: The role of $\mathrm{RE}$ assumptions in institutional design}

When dealing with problems of institutional design, it is important to distinguish three interconnected levels of decisions. First and second order decisions comprise the selection of (normative) criteria and goals of design and the specific rules that are appropriate to meet or realize these criteria. Third order decisions refer to the "object level" of behavioral choices selected by the (future) target actors and beneficiaries of the rules. It has been argued that with regard to first and second order decisions (sometimes called "constitutional decisions"), assumptions of rationality and self-regarding preferences, possibly behind a "veil" in certain moral contexts, can be appropriate even though with respect to third order decisions other models of man may be justifiably used. Behavioral economics and cognitive psychology have produced empirical evidence and also some theoretical insight that limits of rationality and social or intrinsic preferences may affect institutional design in important ways. Individually or socially suboptimal effects which result from boundedly rational behavior (for example, sunk cost effects) create a demand for institutions 
which reduce these inefficiences. This demand arises if the outcomes are evaluated (first order) by RE assumptions.

With respect to non-standard preferences, it is necessary to generate some exante information on the specific distribution of preferences or other characteristics of the (future) target actors whose third order decisions are extrapolated. The acquisition of this knowledge is more likely in cases of small and stable social situations with a fixed population of interacting individuals whose characteristics are wellknown and homogenous. In populations with heterogenous individuals from different cultural contexts and with considerable migration between social contexts, "legislators" will in general not be able to gather much ex-ante-information with regard to the specific mixture of preferences. This information, however, is necessary to estimate whether or not pro-social motives will be undermined to a significant degree by incentives which are provided by the constitutional rules. With regard to normative constitutional theory, the Hume-Buchanan approach towards the construction of universal rules which are valid for an extended time horizon and possibly for a population with a high degree of diversity seems still warranted. Since such constitutional choices will necessarily be made under conditions of high uncertainty with regard to the properties of the affected agents and the specific distribution of social preferences it may be a "quasi-risk aversive" choice (Brennan and Buchanan 1985) to use the standard homo economicus assumptions as a first approximation.

Some additional points which favor the use of RE assumption in analyses of third order decisions are as follows:

1. There is a large set of bounded rationality- and non-selfish motive-models with partially contradictory predictions. It seems impossible to select one element from this set as a theoretical tool suitable for every problem of institutional design. In other words, given that ex-ante knowledge about the properties of the target population is lacking, the use of standard homo economicus assumptions is an obvious alternative.

2. In large-scale aggregate behavior it seems, in general, that homo economicus models and many more complicated alternative theories yield very similar, if not the same, predictions. In this case: Why not use standard RE model?

3. There are institutional domains which require design principles consistent with homo economicus assumptions:

- Competitive, anonymous markets (highspeed trading in financial markets), auctions

- Profit-oriented corporate actors' behavior (in relations with natural persons)

4. Non-standard models are appropriate in special situations involving decisions at the margin, e.g. certain "low cost" situations. However, non-standard models offer no clear predictions about structural variables which affect outcomes of institutional design (e.g. repeated interactions, network effects) and must therefore be combined with standard models. 
Institutional design is, in general, a complex task with considerable uncertainty about its possible effects. Many, if not all, attempts of conscious design are prone to generate non-intended consequences. One should keep in mind that a trial-and-error process of "piecemeal-engineering"(Popper 1966) - albeit guided by theoretical principles - will in general be needed. Starting with RE assumptions, this process of piecemeal-engineering will possibly adopt different behavioral principles referring to third order problems depending on the concrete boundary conditions of the situation. A note of caution has been expressed by celebrated institutional design expert Elinor Ostrom with these words:

The policy of assigning all authority to a central agency to design rules is based on a false conception that there are only a few rules that need to be considered and that only experts know these options and can design optimal policies. Our empirical research strongly challenges this assumption. There are thousands of individual rules that can be used to manage resources. No one, including a scientifically trained professional staff, can do a complete analysis of any particular situation.

(Elinor Ostrom 2005b: 269)

Finally, let me conclude with two false propositions:

1. The RE model represents the uniquely optimal model for institutional analysis.

2. The RE model is useless in institutional analysis.

\section{References}

Becker, Gary S. 1962. "Irrational behavior and economic theory", Journal of Political Economy 70: 1-13 (reprinted in Becker 1976).

Becker, Gary S. 1976. The Economic Approach to Human Behavior. Chicago: University of Chicago Press.

Best, Henning, and Clemens Kroneberg. 2012. "Die Low-Cost-Hypothese”. Kölner Zeitschrift für Soziologie und Sozialpsychologie 64:535-561.

Betts, Alexander, and Paul Collier. 2017. Refuge. Transforming a Broken Refugee System. London: Penguin Books.

Bolton, Gary, Ben Greiner, and Axel Ockenfels. 2013. "Engineering Trust: Reciprocity in the Production of Reputation Information”, Management Science 59: 265-285.

Bowles, Samuel. 2016. The Moral Economy - Why Good Incentives are no Substitute for Good Citizens, New Haven: Yale University Press.

Bowles, Samuel, and Sandra Polania-Rayes. 2012. "Economic Incentives and Social Preferences: Substitutes or Complements?", Journal of Economic Literature 50: 368-425.

Brennan, Geoffrey, and James M. Buchanan. 1985. The Reason of Rules - Constitutional Political Economy, Cambridge: Cambridge University Press (reprinted as Volume 10 of The Collected Works of James M. Buchanan, Indianapolis: Liberty Fund, 2000).

Camerer, Colin F. 2003. Behavioral Game Theory: Experiments in Strategic Interaction, NewYork: Russell Sage.

Coleman, James S. 1974. "Inequality, Sociology, and Moral Philosophy", American Journal of Sociology 80 (3): 739-764. 
Coleman, James S. 1982. The Asymmetric Society. Syracuse: Syracuse University Press.

Coleman, James S. 1990. Foundations of Social Theory. Cambridge, Mass.: Harvard University Press.

Coleman, James S. 1993. "The Rational Reconstruction of Society: 1992 Presidential Address", American Sociological Review 58: 1-15.

Collier, Paul. 2013. Exodus. Immigration and Multiculturalism in the 21st Century, London: Penguin Books.

Dal Bó, Pedro. 2005. "Cooperation under the shadow of the future: Experimental evidence from infinitely repeated games", American Economic Review 95(5): 1591-1604.

Diekmann, Andreas, and Peter Preisendörfer. 2003. "Green and Greenback. The Behavioral Effects of Environmental Attitudes in Low-Cost and High-Cost Situations". Rationality and Society 15:441-472.

Diekmann, Andreas, Ben Jann, Wojtek Przepiorka, and Stefan Wehrli. 2014. "Reputation Formation and the Evolution of Cooperation in Anonymous Online Markets", American Sociological Review 79(1): 65-85.

Durkheim, Emile. 1895. Les règles de la méthode sociologique. Paris: Presses Universitaires de France (18th ed., 1973).

Esser, Hartmut, and Clemens Kroneberg. 2015. "An Integrative Theory of Action: The Model of Frame Selection”, pp. 63-85 in: Lawler, Edward J., Shane R. Thye, and Jeongkoo Yoon (eds.), Order on the Edge of Chaos: Social Psychology and the Problem of Social Order. New York: Cambridge University Press.

Falk, Armin, and Urs Fischbacher. 2005. "Modeling Strong Reciprocity”, pp. 193-214 in: Moral Sentiments and Material Interests. Edited by Herbert Gintis, Samuel Bowles, Robert Boyd, and Ernst Fehr. Cambridge, Mass.: MIT Press.

Ford, Jonathan. 2016. "'Spoofing' case highlights perils of automated trading”, Financial Times November 13, 2016 (online version: https://www.ft.com/content/a60b4c4c-a988-11e6-809dc9f98a0cf216).

Frey, Bruno S. 1994. "How Intrinsic Motivation is Crowded Out and In", Rationality and Society 6: 334-352.

Gintis, Herbert. 2017. Individuality and Entanglement. The Moral and Material Bases of Social Life, Princeton: Princeton University Press.

Greif, Avner. 2006. Institutions and the Path to the Modern Economy, Cambridge: Cambridge University Press.

Harsanyi, John C. 1958. "Ethics in Terms of Hypothetical Imperatives", Mind 67: 305-316 (reprinted in Harsanyi 1976).

Harsanyi, John C. 1976. Essays on Ethics, Social Behavior, and Scientific Explanation. Dordrecht: Reidel.

Harsanyi, John C. 1977. Rational Behavior and Bargaining Equilibrium in Games and Social Situations. Cambridge: Cambridge University Press.

Harsanyi, John C. 1978. "Bayesian Decision Theory and Utilitarian Ethics", American Economic Review 68(2): 223-228.

Hausman, Daniel. 1998. "Rationality and Knavery”, pp. 67-79 in: Werner Leinfellner and Eckehart Köhler, eds. Game Theory, Experience, Rationality; Foundations of Social Sciences; Economics and Ethics: In Honor of John C. Harsanyi. Dordrecht: Kluwer.

Herrmann, Benedikt, Christian Thöni, and Simon Gächter. 2008. “Antisocial Punishment Across Societies", Science 319: 362-367.

Hume, David. 1741. "Of the Independency of Parliament”, pp. 40-47 in Essays Moral, Political, and Literary. edited by Eugene F. Miller. Indianapolis: Liberty Press Classics, 1985.

Jacob, Brian A., and Steven Levitt. 2003. "Rotten Apples: An Investigation of the Prevalence and Predictions of Teacher Cheating”, Quarterly Journal of Economics 118: 843-877. 
Kahneman, Daniel, and Amos Tversky. 1986. "Rational Choice and the Framing of Decisions", S. 67-94 in: Robin M. Hogarth \& Melvin W. Reder (eds.), Rational Choice, Chicago: University of Chicago Press.

Kahneman, Daniel. 2011. Thinking, Fast and Slow. London: Allen Lane.

Lazear, Edward P. 2000. "Performance Pay and Productivity", American Economic Review 90 (5): 1346-1361.

Levitt, Steven D., and John List. 2007. "What Do Laboratory Experiments Measuring Social Preferences Reveal About the Real World?”, Journal of Economic Perspectives 21(2): 153-174.

Levitt, Steven D., and John List. 2008. “Homo Economicus Evolves”, Science 319: 909-910.

Machina, Mark. 1987. "Decisions under Uncertainty: Problems Solved and Unresolved”, Journal of Economic Perspectives 1:121-154.

Ostrom, Elinor. 2005a. Understanding Institutional Diversity. Princeton: Princeton University Press.

Ostrom, Elinor. 2005b. "Policies that crowd out reciprocity and collective action", Pp. 253-276 in: Moral Sentiments and Material Interests. Edited by Herbert Gintis, Samuel Bowles, Robert Boyd, and Ernst Fehr. Cambridge, Mass. MIT Press.

Popper, Karl R. 1966. The Open Society and Its Enemies, (Two Volumes). Fifth ed., London: Routledge \& Kegan Paul.

Posner, Eric. 2013. “The Institutional Structure of Immigration Law”, The University of Chicago Law Review 80: 289-313.

Rai, Tage S., and Daniel Diermeier 2015. "Corporations as Cyborgs: Organizations elicit anger but not sympathy when they can think but not feel", Organizational Behavior and Human Decision Processes 126: 18-26.

Raub, Werner. 2017. Rational Models, Utrecht: Universiteit Utrecht (expanded version of a farewell lecture as Dean).

Raub, Werner, and Jeroen Weesie. 1990. "Reputation and Efficiency in Social Interactions", American Journal of Sociology 96: 626-654.

Raub, Werner, and Chris Snijders. 1997. "Gains, Losses, and Cooperation in Social Dilemmas and Collective Action: Effects of Risk Preferences”, Journal of Mathematical Sociology 22: 263-302.

Raub, Werner, Vincent Buskens, and Vincenz Frey. 2013. "The rationality of social structure: Cooperation in social dilemmas through investments in and returns on social capital", Social Networks 35(4): 720-732.

Rawls, John. 1971. A Theory of Justice. Cambridge, Mass.: Harvard University Press.

Underhill, Kristen. 2016. "When Extrinsic Incentives Displace Intrinsic Motivation: Designing Legal Carrots and Sticks to Confront the Challenge of Motivational Crowding-Out", Yale Journal on Regulation 33: 213-279.

Schüssler, Rudolf. 1988. "Der Homo Oeconomicus als skeptische Fiktion”, Kölner Zeitschrift für Soziologie und Sozialpsychologie 40: 447-463.

Schüssler, Rudolf. 1990. "Threshold Effects and the Decline of Cooperation”, Journal of Conflict Resolution 40: 476-494.

Simon, Herbert A. 1978. "Rationality as Process and as Product of Thought", American Economic Review 68 (No. 2, Papers and Proceedings): 1-16.

Thaler, Richard. 1980. "A Positive Theory of Consumer Choice", Journal of Economic Behavior and Organization 1: 39-60.

Thaler, Richard. 2015. Misbehaving: The Making of Behavioral Economics, New York: Norton.

Thaler, Richard, and Cass R. Sunstein. 2008. Nudge: Improving Decisions about Health, Wealth, and Happiness, New Haven: Yale University Press.

Tutic, Andreas, Thomas Voss, and Ulf Liebe. 2017. "Low-Cost-Hypothese und Rationalität. Eine neue theoretische Herleitung und einige Implikationen”. Kölner Zeitschrift für Soziologie und Sozialpsychologie 61: 651-672. 